\title{
Organizational and individual determinants of patent production of academic scientists and engineers in the United States
}

\author{
Wan-Ling Huang, Mary K Feeney and Eric W Welch
}

\begin{abstract}
This article contributes to an important literature on the determinants of academic patenting. We develop and test a model that predicts how individual characteristics and organizational factors affect individual patenting production. The analysis uses zero-inflated negative binomial regression on data from a 2010 national survey of 1,379 US-based university scientists and engineers, 624 of which hold no patents assigned to their current university. Findings from this research generally support our hypotheses that individual and organizational factors are associated with individual patent production. We find that while university patent policy and university technology transfer offices may be important for encouraging or discouraging scientists to patent the first time, department incentives and individual preferences and characteristics predict the number of patents that faculty produce. This research supports prior literature and develops new perspectives on how universities and policy-makers can understand and shape how individual and organizational constraints and incentives affect patent productivity.
\end{abstract}

$O$ INCE THE 1970S, US universities have shifted their role beyond the linear model, producing pure basic science (Bush, 1945), toward a richer perspective which emphasizes universities' role in fostering technology development and economic performance (Etzkowitz, 2008). This shift in activities and outcomes is a result of multiple demands on universities (Coriat and Orsi, 2002), including industrial demand for technology transfer and the need for universities to acquire industry

\footnotetext{
Wan-Ling Huang (corresponding author), Mary K Feeney and Eric W Welch are at the Science, Technology and Environment Policy Lab, Department of Public Administration, COPPA Hall, M/C 278, 412 South Peoria Street, University of Illinois at Chicago, Chicago, IL 60607, USA; Email: whuang24@uic.edu; mkfeeney@uic.edu; ewwelch@uic.edu.

The authors wish to thank the anonymous reviewers for their constructive comments on the earlier version of the article. Data analyzed in this article were collected under the auspices of the two-year (2008-2010) research project titled 'Patenting Behavior of Academic Scientists and Engineers: a Micro-level Analysis of the Factors that Determine the Production of University Patents', funded by US National Science Foundation (Grant \# SES-0750613; PI: Dr Eric Welch).
}

funding and alternative sources of income (e.g. royalty profits) (Sanz-Menéndez and Cruz-Castro, 2003). Through legislation, the federal government has actively sought to stimulate the transfer of 'deliverables' from universities (Mowery and Sampat, 2005). For example, the 1980 Bayh-Dole Act provided blanket permission for universities to patent and license technologies developed with federal funding. Additionally, universities have set internal incentives (e.g. share of royalty income) to encourage faculty to engage in more patentable research that might result in economic profits (Lach and Schankerman, 2008) and have established technology transfer offices (TTOs) to assist faculty with research commercialization (Feldman et al., 2002).

While federal policies and university efforts have aimed at encouraging and enabling academic scientists to engage in patenting activities, there is limited research investigating the factors that explain variation in the patenting outcomes of an individual faculty (Audretsch and Kayalar-Erdem, 2005; Carayol, 2007; Stephan et al., 2007). Most research on university patenting focuses primarily on aggregate analyses of temporal changes in quantity and quality of university patents, their impact and utilization, 
Wan-Ling Huang is a PhD candidate at the Department of Public Administration, University of Illinois at Chicago. She conducts research in the areas of research collaboration, public sector voluntary initiatives and patenting behavior of academic scientists and engineers. Her doctoral dissertation investigates institutional and individual determinants of university scientists' decisions to seek intellectual property protection in the US context.

Mary K Feeney is an Assistant Professor in Public Administration at the University of Illinois at Chicago. She is interested in public management, sector distinctions, and science and technology policy. Feeney is working on research investigating patenting at universities, rules and red tape, and comparing public and nonprofit organizations. Feeney holds a PhD in public administration and policy from the University of Georgia and a master's degree in public policy from Rutgers University, New Brunswick. Her most recent book, co-authored with Barry Bozeman, is Rules and Red Tape: a Prism for Public Administration Theory and Research (M E Sharpe, Inc., April 2011).

Eric W Welch is an Associate Professor and director of the Science, Technology and Environment Policy Lab in the Department of Public Administration at the University of Illinois at Chicago. His research focuses at the nexus of science policy, environmental policy, and R\&D performance evaluation. Professor Welch currently oversees funded projects examining the patenting behavior of academic scientists, the role of professional networks in career success of women and minority academic scientists, and the patterns of exchange and use of genetic resources for science and innovation. His research has been published in such journals as Research Policy, Policy Sciences, and Journal of Public Policy and Management.

and their distribution by class (Berkovitz et al., 2001). However, the 'inherent patentability' of research is probably not a complete explanation of university patenting in particular individual faculty members' propensity to patent, given that the chief force behind the surge in patenting is due to the increased efforts of university administrators to encourage commercialization instead of some change in the type of research universities perform (Thursby and Thursby, 2002). In response, this study investigates the effect of individual characteristics and organizational factors on scientists' patenting production.

We consider that an individual's patenting activities can be explained in terms of the constraints that delimit the scientist's assessments of commercialization opportunities. Therefore, we ask:

1. What individual characteristics - such as career status, publishing activity, and scientists' attitudes towards open science — affect patenting production of academic scientists in US universities?

2. What organizational factors - such as perceived patenting incentives and perceived effectiveness of the TTO - affect patenting production of academic scientists in US universities?

In addition to the reasons outlined above, we contend that an examination of the individual and organizational factors that motivate university patent production is warranted because universities produce patents at varying levels resulting in economic and other impacts (Mowery and Ziedonis, 2002). Additionally, university patenting appears to result from the increased propensity of researchers to patent, rather than changes in the underlying faculty research and behaviors (Henderson et al., 1998). Our approach is also important because patents are recognized to be an imperfect, yet reasonable indicator of economically and socially valuable innovative output from research-derived knowledge (Griliches, 1990; Salter and Martin 2001). Thus, understanding why some scientists produce no patents while others continue to patent is important for understanding how patenting is integrated in the university knowledge production model.

Findings from this study provide insights into broader policy issues and inform university management about how to design appropriate organizational systems that encourage and enable scientists to engage in patenting. In the next section, we review the relevant literature on patenting outcomes of academic scientists and engineers, with a particular focus on the individual and organizational attributes that influence patent production. Based on this discussion we propose a set of hypotheses and our model before describing the data, measures, and methods and presenting the regression estimation results. We conclude with a discussion of the broader implications of our findings.

\section{Literature and hypotheses}

Prior research investigating patenting activities of university inventors has identified several factors that explain scientists' engagement in the patenting process (Azoulay et al., 2007; Baldini, et al., 2005, 2007; Owen-Smith and Powell, 2001; Thursby and Thursby, 2002). These factors can be categorized as individual characteristics and organizational factors. Below we discuss the relationships between individual and organizational factors related to university patenting activities and our model, determinants of individual academic patent production (Figure 1), which illustrates the relationships between individual and organizational factors and individual patenting outcomes at the scientist level of analysis.

\section{Individual characteristics}

Because academic patenting activity is typically considered to be conducted outside of or in addition to traditional activities required of academic researchers (e.g. research, teaching, and service), it is often described as entrepreneurial activity (Rothaermel et al., 2007). Louis et al. define academic entrepreneurship as the attempt to increase individual or organizational profit, influence, or prestige through the development and marketing of research ideas or research-based products (1989: 111). 


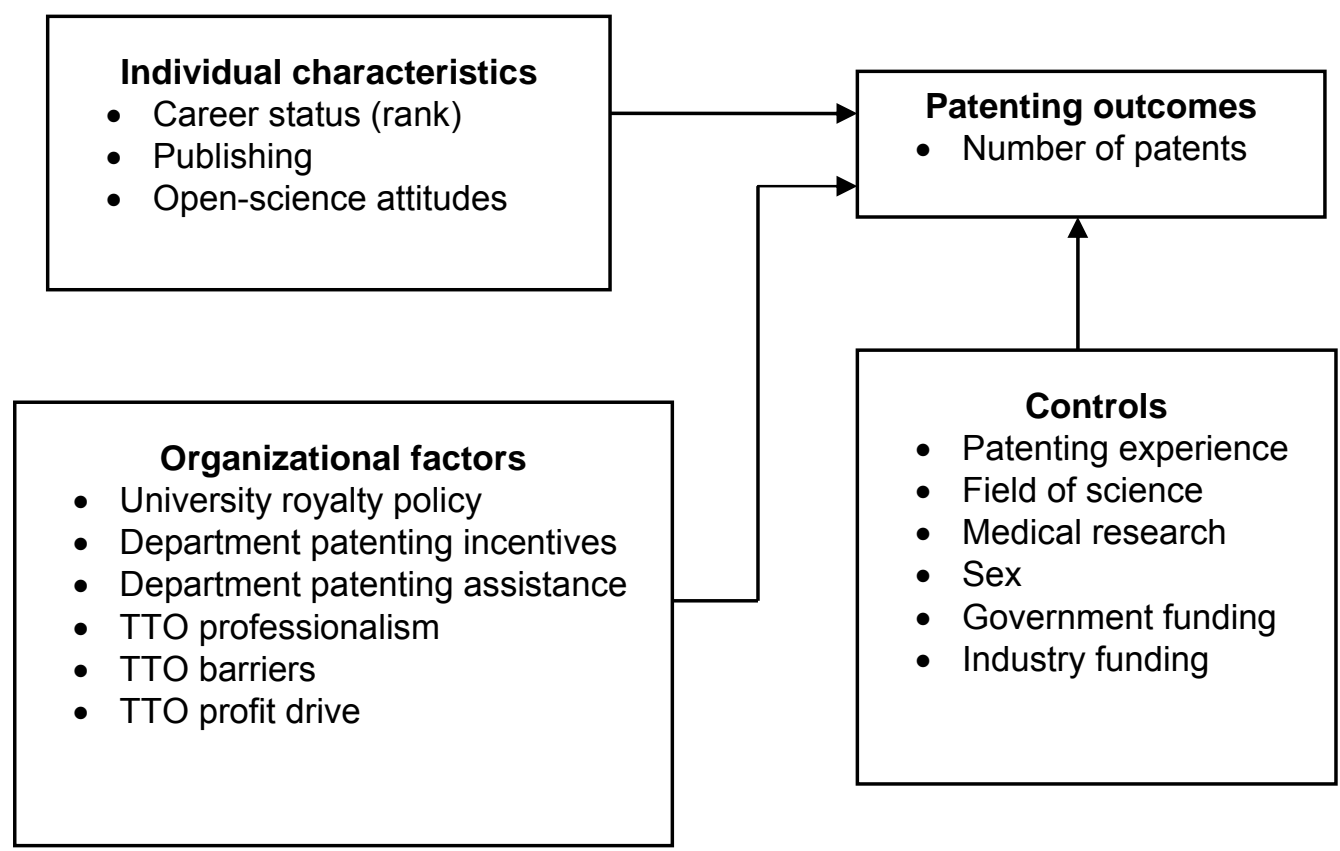

Figure 1. Determinants of individual academic patent production

Brockhaus and Horwitz (2002) argue that personal and psychological characteristics are important determinants of entrepreneurship, because those characteristics influence individuals' attitudes and perceptions related to new opportunities. Personal characteristics include age, rank, prestige, and productivity, while psychological factors may include attitudes toward patenting, perceived risk, or perceived benefits of patenting. For example, a younger, risk-seeking scientist may perceive patenting as an opportunity to explore a broader career path rather than as a deviation from traditional academic reward structures. We develop hypotheses related to three individual factors: career status, publishing, and attitudes toward open science.

Career status Prior research anticipates significant relationships between a scientist's career status and patenting outcomes, though the direction of the relationship is inconclusive. Are junior scientists more likely to patent when trained in an environment in which commercialization of university research is more common? Are senior scientists who face more flexible productivity demands more likely to engage in patenting activities? Some argue that doctoral student training is critical to understanding patenting activities. If the academic career is path-dependent (Ambos et al., 2008), scientists who have been socialized in a non-patenting environment may lack the capacity and motivation to adopt new, unfamiliar activities that lead to patenting and are thus less likely to patent.

Conversely, Bercovitz and Feldman (2008) show that junior scientists who have been trained in an environment where research commercialization is increasingly considered a part of the mission of modern universities are more likely to engage in technology transfer through invention disclosure than senior scientists who were not trained in such an environment. Accordingly, junior faculty who were trained in a post-Bayh-Dole era may be more likely to engage in patenting activities (Renault, 2006).

In contrast, others argue that successful senior scientists, advantaged by their tenured positions, will have more flexibility and freedom to engage in nontraditional academic work (Moutinho et al., 2007). In fact, some argue that job security offers senior scientists the freedom to engage in technology development in addition to basic scientific research. Consistent with the life-cycle model suggested by Levin and Stephan (1991), scientists in early career stages will devote time to publishing in order to attain promotion and tenure, while those in tenured positions will consider broader career paths to enhance personal earning or recognition in the field (Stephan et al., 2007).

Additionally, senior scientists, who have successfully built academic careers, will be more capable of adapting to evolving reward systems, and will have more resources to patent and to encourage such activities among those working in their labs. Recent empirical research has found that senior scientists are more active in patenting inventions than junior scientists (Buenstorf, 2009; Stephan et al., 2007; Thursby et al., 2007).

While there is empirical research supporting both the path-dependent and the life-cycle models, our perspective aligns with the life-cycle model. We consider patenting activities an additional type of entrepreneurial activity that requires capacity, resources, and time. Even when junior faculty have been trained in an environment that encourages patenting at the university, their patenting activities may be constrained by limited time and resources available for research commercialization, especially 
given that current academic promotion systems continue to value publications more than patents. In light of previous findings, we expect that seniority will be positively related to patenting activities.

\section{H1: Compared to junior scientists, senior scientists will be more likely to patent.}

Publishing There has long been interest in the research literature about whether publishing and patenting activities are substitutive or complementary. Several arguments for the substitution or crowding-out effect have been put forward in the literature, including the following:

1. A scientist's time and resources are limited; those who publish extensively have less time to undertake patent-related activities (Fabrizio and Di Minin, 2008);

2. A researcher may have reasons to maintain secrecy around discoveries, thus withholding or delaying publications (Murray and Stern, 2007; Thursby and Thursby, 2002);

or

3. Intentions to patent may shift a scientist's interests from basic research to applied research (Geuna and Nesta, 2006), especially in fields that offer higher technology opportunities.

In sum, there are a number of reasons why we might expect shifts toward patenting activities to distract academic scientists from publishing activities.

Fabrizio and Di Minin (2008) have found that researchers who repeatedly patent produce lowerquality publications (as measured by citations). Jensen et al. (2003) point out that the most productive faculty are less likely to disclose their inventions and spend less time engaging in future development. While these examples argue that patenting and publishing activities are essentially substitutive, most of the empirical literature has shown that there is no effect of one on the other (Agrawal and Henderson, 2002) and, instead, that patenting and publishing are complementary (Ambos et al., 2008; Azagra-Caro et al., 2007; Azoulay et al., 2007; Buenstorf, 2009). The primary reasons for the complementarity of the two activities are related to the nature of the knowledge produced, the creation of collaborative networks, and the balance of patenting and publishing incentives.

First, patenting and publishing are complementary because of the dual-use nature of the knowledge outputs from academic research (Agrawal and Henderson, 2002; Stephan et al., 2007).

Second, collaborative networks with industry enable complementary patenting and publishing activities. When a scientist works with industry, the relationship provides new perspectives on application, opportunities for funding, and introductions to new research ideas (Franzioni, 2009; Stephan et al., 2007).
Finally, department, university, and broader fieldlevel incentives may increase the benefits derived from patenting to a level that scientists seek to integrate patenting and publishing activities (OwenSmith and Powell, 2001; Dai et al., 2005; Baldini et al., 2005). As universities aim to encourage technology development while not reducing their commitment to publishing, it is likely that the university and academic scientists and engineers will develop mechanisms to simultaneously maximize the benefits that accrue from attaining both goals.

Given that the preponderance of the empirical evidence falls on the complementary side, we expect to find a positive association between publishing output (measured as peer-reviewed journal articles) and patenting activity.

\section{H2: Scientists who demonstrate increased publish- ing activity will be more likely to patent.}

Open-science attitudes The shift in US universities toward greater encouragement of technology development, technology transfer, and economic performance (Etzkowitz, 2008; Coriat and Orsi, 2002; Sanz-Menéndez and Cruz-Castro, 2003; Mowery and Sampat, 2005) represents a fundamental organizational change that could affect the norms of expected scientific behavior. As the transition continues, traditional norms will combine with new norms that are reflected in incentive systems, which can vary across department, university, and field of science. Hence, scientists' attitudes toward traditional norms of science may represent their acceptance of or experience with the transition toward technology transfer and may be important determinants of patent production.

Traditional science norms are widely recognized to include universalism, communism, disinterestedness, and organized skepticism (Merton, 1942). Universalism demands that valid scientific research is based on pre-established criteria. Communism the open-science norm - requires that scientific knowledge is owned by the community and is publicly available. Disinterestedness requires that personal interests do not interfere with the search for truth through scientific research. Organized skepticism ensures that scientific knowledge development is carefully scrutinized by peers. These norms are mutually supportive. For example, the open-science norm favors public accessibility of data, methodologies, and knowledge such that peers can scrutinize the conduct of science and replicate findings in the pursuit of knowledge.

Some researchers (Powell and Owen-Smith, 1998) contend that the rise of intellectual property (IP) protection has changed the norm of open science, especially in the life sciences, while others argue that new norms recognizing IP and economic returns do not override traditional norms. Some argue that IP protection is compatible with an open-science norm because the patenting process represents an 
additional form of review, beyond peer review, to ensure scientific quality; patent information is publicly available; and ownership of intellectual property does not necessarily result in exclusion of public access because not all granted patents are licensed exclusively (Mowery et al., 2001; Ostrom and Hess, 2005).

In fact, one might argue that the licensing of patents enables wider use of academic knowledge. For example, according to the nationally representative survey data used in this study, about one-third of academic scientists who patent report that they regularly use information from other researchers' patents to inform and advance their own research.

Academic scientists who believe that the proprietary realm of technology is compatible with openscience norms may be more likely to patent. For them, patenting does not interfere or conflict with traditional norms (universal standards, the primacy of the pursuit of knowledge, scrutability, and openness). Patenting reinforces traditional norms because it provides another way to disseminate research findings or represents an incentive mechanism for scientists to invest in the production of scientific knowledge that could be applied and commercialized (David, 2004).

By contrast, advocates of open science point to the social benefits that result from maximizing the potential scientific returns of new knowledge. For academic scientists who have been socialized in a culture of open science, privatizing research-based products is perceived as decreasing the social and public value of new knowledge and leading to the duplication of research (Dasgupta and David, 1994). Similarly, secreting university-based scientific information through patenting may prevent research from public examination and peer review, and place proprietary interests ahead of the pursuit of knowledge (Mazzoleni and Nelson, 1998). Therefore, academic scientists who have been strongly socialized according to traditional norms of open science may choose not to patent because intellectual property and secrecy prevents public access and can make replication difficult.

Given that the university system is in transition and that attitudes toward the extent to which patenting interferes with open-science norms varies, we expect that individuals who believe that openscience norms and intellectual property protection are compatible will be more likely to engage in patenting activities than those who believe that intellectual property protection is contradictory to openscience norms. By compatibility, we mean that intellectual property protection is perceived in a way that not only promotes research commercialization, but also contributes to the pool of scientific knowledge. Conversely, individuals who strongly favor the open-science norm will tend to view patenting activities as distracting the academic scientific community from producing publicly available research. We hypothesize the following:

\section{While personal and psychological characteristics are important for understanding patenting behavior among individuals, they do not explain the ways in which organizations help or hinder patenting activities}

H3: Scientists who have positive, open-science attitudes will be less likely to patent.

\section{Organizational factors}

While personal and psychological characteristics are important for understanding patenting behavior among individuals, they do not explain the ways in which organizations help or hinder patenting activities. Organizations can influence individual members' behavior through, for example, the establishment of rules and expectations, provision of resources and support, and the integration of skills and abilities to produce desired outcomes (Gioia et al., 1994). Just as universities establish expectations for scientists to engage in research activity through promotion and tenure policies, teaching loads, and the requirements for research funding, universities also shape academic scientists' patenting behavior. For example, universities create and reinforce campus-level patenting norms through public recognition of patenting activity or by establishing formal organizational policies and regulations related to disclosures and royalty-sharing.

Research indicates that organizational factors outside the research process influence academic scientists' choice of a knowledge-diffusion method: publishing or patenting (Dai et al., 2005). Universities and departments can design a culture of patenting which increases researchers' perception of the potential benefits and reduces apparent costs of such activities (Owen-Smith and Powell, 2001). Potential benefits could be tangible such as personal earnings or intangible such as reputation and visibility (Baldini et al., 2005). For example, Friedman and Silberman (2003) contend that universities providing greater monetary rewards (e.g. royalty shares) for inventors will generate more licenses and license income. In contrast, Baldini et al. (2007) argue that intangible rewards (e.g. visibility and reputation) are more relevant than personal earnings to motivating patenting behavior. Because of the structure of universities, it is possible that these tangible and intangible rewards occur at the university level (e.g. royalty-sharing) or at the department level (e.g. salary increases, promotion). We expect that universities and departments that offer tangible and intangible 
rewards for patenting activities will see an increase in patenting activities. That is, a work environment that values and rewards patent production will encourage individual scientists to patent.

\section{H4: Scientists who work in university organizations that more strongly encourage entrepreneurial behavior will be more likely to patent.}

One of the most important formal organizations that can affect university-based patenting activities is the technology transfer office (TTO) or its equivalent (e.g. office of technology management). TTOs are university organizations or centers charged with pursuing, protecting, packaging, and licensing IP generated from the university research enterprise. TTOs are responsible for identifying patentable inventions, assisting with the patenting process, and negotiating with licensees for access to the IP generated by university-based faculty, staff, and students.

Research indicates that the existence, capacity, and experience of the TTO are critical determinants of a university's 'patenting capacity' (Baldini et al., 2005, 2007; Owen-Smith and Powell, 2001). The TTO is an intermediate organization that assists with communication among university inventors, the US Patent and Trademark Office (USPTO), and industry licensees. The TTO plays an important role in the patenting process by raising awareness about IP protection, disseminating practical information about invention disclosure and patenting, providing assistance and service to scientists, determining which patents and licenses to file and pursue, and facilitating the transfer of technology from university researchers to the marketplace.

Given that university objectives are more diverse than the simple pursuit of economic profits, the effectiveness of a TTO may be evaluated based on multiple criteria, including responsiveness to clients, royalty fees generated, sponsored research funds negotiated, contributions to innovation and economic development, and so on (Thursby et al., 2001). Thus, effective TTOs require the scientific and technological knowledge to evaluate the patentability of underlying inventions and the expertise for identifying commercialization opportunities and potential licensees. While there are multiple ways in which we might evaluate TTO effectiveness from an objective standpoint, it is equally important that academic scientists perceive the TTO as effective. Because the TTO facilitates patent disclosure and licensing and because the disclosure of IP is voluntary, it is critical that academic scientists view the TTO as competent and capable of managing the patenting process. We expect that academic scientists will be more likely to successfully interact with TTOs that they perceived as effective and professional.

While it can be difficult to measure an organization's effectiveness, researchers have investigated the relationships between TTO age and professionalism and patenting outcomes. The TTO plays a critical role in identifying patentable inventions; it manages the paper work and administrative procedures associated with patent disclosure and submission. Therefore, experienced TTOs should reduce inventors' burdens by offering necessary assistance. Friedman and Silderman (2003) found that universities with more experienced TTOs, measured by age, generate more licenses and license income. Siegel et al. (2003) found that an increase in TTO staff had a positive effect on the production of university licensing agreements. Lach and Shankerman (2008) conclude that the impact of university monetary incentives on the generation of license income is mediated by TTO capacity. Given that empirical studies generally support the idea that the establishment of a TTO has a positive effect on university patenting activities (Ambos et al., 2008; Coupe, 2003) and that TTO capacity is associated with increased patent-related activities, we expect that perceived TTO effectiveness will be positively related to scientists' patenting activity.

H5: Scientists who work in universities that have more effective technology transfer offices will be more likely to patent.

Based on the theoretical discussion and the findings of empirical studies explored above, we propose a model to conceptualize the relationships between individual characteristics and organizational factors and patenting outcomes. Figure 1 illustrates our model for the determinants of individual academic patent production. The left side of the model notes two categories of variables, individual characteristics and organizational factors, and their relationship to patenting outcomes. Individual characteristics include career status, publishing, and open-science attitudes. Organizational factors include university royalty policy, department patenting incentives, department patenting assistance, and perceived TTO professionalism, barriers, and profit drive. Controls include patenting experience as a $\mathrm{PhD}$ student, field of science, medical research, sex, and funding sources.

\section{Data, variables, and method}

\section{Data}

The data come from a 2010 national survey of academic scientists in the USA, some of whom have patented and some who have not. In the study, the population of patenters is defined as scientists and engineers who are:

1. listed as inventors on all 7,506 patents granted by USPTO in 2006 in which

2. the patent is assigned to a US university, and

3. the individual is actively working as a researcher in a US university. 
After removing non-university inventors and adjusting for unavailable or invalid email addresses, the patenter sample included 3,032 individuals. To develop the non-patenter sample, we randomly selected 1,600 of the patenters and paired each one with a randomly selected non-patenter from the patenter's academic department. Non-patenters were defined as individuals who, according to the USPTO public online databases, ${ }^{1}$ have never been awarded a patent. Therefore, the sample frame of 4,632 individuals included a census of academic patenters from 2006 and a randomly selected matched sample of academic non-patenters, based on academic department.

After conducting a pre-test on a set of 200 individuals (134 patenters; 66 non-patenters) randomly selected from the sample frame, the final survey was administered to 4,432 academic scientists and engineers (2,898 patenters; 1,534 non-patenters). Of the 1,610 responses, 118 were removed due to insufficient information, misidentification, or ineligibility. The final response size was 1,492 completed surveys. According to the RR4 method of the American Association for Public Opinion Research (2009), the response rate was $36 \%$ for the patenter group and $33 \%$ for non-patenters. For this analysis, we use the subset of 1,379 scientists and engineers who have an academic rank of assistant, associate, or full professor.

The online survey instrument collected data on patenting activity including topics such as patenting and disclosure experience, perceptions of the organizational context relevant to patenting, personal values and attitudes towards university patenting, and general questions about individual career trajectory, research activity, and productivity.

\section{Dependent variable}

We capture the extent of patenting activity of academic scientists and engineers using the variable number of patents. This variable is measured as the total number of university patents for which the respondent is listed as an inventor at the university where they currently work ${ }^{2}$ and ranges from 0 to 157 with a mean of 4.27 .

\section{Independent variables}

We measure the three individual characteristics: career status, publishing, and open-science attitudes with five variables. Respondent career status is captured with three dummy variables for academic rank (and thus seniority), assistant professor, associate professor, and full professor. Approximately $18 \%$ of respondents are assistant professors and $22 \%$ are associate professors. Publishing is measured by the sum of the respondent's peer-reviewed academic publications in the past two years, including journal articles and conference proceedings. While this variable does not measure the quality of these publications, it does capture the scientist's capacity to conduct and publish peer-reviewed research. Publishing ranges from 0 to 176 with a mean of 13.02 . Open-science attitudes is the sum of responses (level of agreement) to the following items:

1. Commercial opportunity distracts academic scientists from doing good research; ${ }^{3}$

2. Publishing and protecting IP are two goals that are fully compatible in modern universities;

3 . Patenting activity reduces the ability to present research findings at conferences and other public venues; and

4. Pressures to patent prevent faculty from focusing on publishable research.

Open-science attitudes measures the extent to which the respondent favors open-science norms and ranges from 4 to 16 , with 16 indicating that the respondent believes IP protection conflicts with the conduct of science (scale reliability test: $\alpha=0.74$ ).

We include six organization variables: university royalty policy, department patenting incentives, department patenting assistance, TTO professionalism, TTO barriers, and TTO profit drive. The first three variables operationalize organizational incentives and capacity. University royalty policy is a dummy variable $(1=$ university has a formal policy for distributing the patent royalties). ${ }^{4}$ Existence of patent policy signals the university's attempt to legitimize patenting activities and encourage patenting (Baldini et al., 2007). Department patenting incentives is the sum of responses (level of agreement) to the following items:

1. In my department, it is important for junior faculty to patent; and

2. Patenting is an important indicator of scholarship in my department.

This variable reflects the extent to which the department considers patenting to be an important component of a scientist's output portfolio. Because important decisions such as tenure and promotion are made at the department level (Renault, 2006), departmental recognition of patenting as an important scholarly activity provides an indicator of the incentive structure. Department patenting incentives range from 2 to 8 , with 8 indicating strong department encouragement and appreciation of patenting (scale reliability test: $\alpha=0.68$ ). Department patenting assistance is a dummy variable, which is coded 1 if there is a knowledgeable faculty or staff member in the department responsible for helping faculty with invention disclosure and patenting activities. This variable represents whether the department has the capacity to provide resources to scientists to engage in patenting activities. Among respondents, $23 \%$ indicated that their department had this type of assistance.

The three organizational measures capture the respondent's perceptions of TTO effectiveness. These 
measures were constructed using factor analysis with varimax rotation on a multi-item question related to the respondent's university TTO. The first construct, TTO professionalism, is a variable based on a factor loading of three survey items:

1. The TTO at my university provides high-quality service to faculty;

2. The TTO at my university is very active in identifying patentable research; and

3. The TTO at my university has sufficient scientific and technological knowledge to evaluate the patentability of invention disclosures.

Measured as the saved factor score, this variable represents the scientist's perception of the professional knowledge and expertise of the university's TTO. TTO barriers is operationalized as the factor loadings on two survey items:

1. The TTO at my university is a highly bureaucratic organization; and

2. The TTO at my university is only interested in certain fields or disciplines, especially those that have generated royalties.

TTO barriers is an indicator of the extent to which scientists perceive that the TTO facilitates patenting activity. TTO profit drive is measured by the factor score of responses to the following two items:

1. Typically, the TTO at my university is not inclined to file a patent application with USPTO unless a licensee has been identified; and

2. The TTO at my university covers all patenting fees.

TTO profit drive captures the profit motives of the TTO. A profit-driven TTO is more likely to file patents only when a licensee has been identified and is less likely to cover patent fees. For TTO professionalism, TTO barriers, and TTO profit drive, a higher score indicates, respectively, that the TTO is more professional, has higher barriers, and is more profit-driven. The factor analysis results are reported in Table 1.

\section{Control variables}

We control for other factors that may influence patenting outcomes including: patenting experience, field of science, medical research, sex, and percentage of government and industry funding. Because those who are experienced with the patenting process are more likely to patent in the future (Shane, 2000), we control for the respondent's patenting experiences with a dummy variable $(1=$ respondent was involved in patenting activities as a $\mathrm{PhD}$ student). In our data, $16 \%$ of respondents report having patenting experiences as a $\mathrm{PhD}$ student.

Because technological opportunity and type of research funding varies across field of science, we include dummy variables for the following fields: engineering, biological sciences, chemistry, computer science, medical sciences, physics, and other. Other is a diverse group of fields including, for example, earth science and mathematics, none of which has sufficient representation in the sample to warrant a separate field designation. Approximately $33 \%$ of respondents are from engineering, $27 \%$ from non-medical biological sciences, $15 \%$ from chemistry, 3\% from computer science, $13 \%$ from medical sciences, and $6 \%$ from physics.

We also asked all respondents to indicate if they conduct medical research, because researchers working in medical research are more likely to bridge the gap between basic and applied research and typically have more opportunities to engage in technology transfer activities (Sine et al., 2003; Stephan et al., 2007). This is a valid addition because there is only a 0.34 correlation between the variable for the medical science field and the conduct of medical research; many individuals outside the field of medical

Table 1. Exploratory Factor Analysis for TTO Measures

\begin{tabular}{|c|c|c|c|}
\hline & $\begin{array}{c}\text { TTO } \\
\text { Professionalism }\end{array}$ & $\begin{array}{c}\text { TTO } \\
\text { Barriers }\end{array}$ & $\begin{array}{c}\text { TTO } \\
\text { Profit Drive }\end{array}$ \\
\hline The TTO at my university provides high quality service to faculty & 0.810 & -0.309 & -0.106 \\
\hline The TTO at my university is very active in identifying patentable research & 0.865 & -0.125 & -0.161 \\
\hline The TTO at my university is a highly bureaucratic organization & -0.294 & 0.753 & 0.035 \\
\hline $\begin{array}{l}\text { The TTO at my university is only interested in certain fields or disciplines, } \\
\text { especially those that have generated royalties }\end{array}$ & -0.123 & 0.852 & 0.114 \\
\hline $\begin{array}{l}\text { The TTO at my university has sufficient scientific and technological } \\
\text { knowledge to evaluate the patentability of invention disclosures }\end{array}$ & 0.829 & -0.130 & -0.078 \\
\hline $\begin{array}{l}\text { Typically, the TTO at my university is not inclined to file a patent application } \\
\text { with USPTO unless a licensee has been identified }\end{array}$ & -0.103 & 0.391 & 0.705 \\
\hline The TTO at my university covers all patenting fees & -0.144 & -0.087 & 0.871 \\
\hline $\begin{array}{l}\text { Total Eigenvalues } \\
\% \text { of Variance }\end{array}$ & $\begin{array}{r}3.025 \\
43.208\end{array}$ & $\begin{array}{r}1.086 \\
15.521\end{array}$ & $\begin{array}{r}1.009 \\
14.419\end{array}$ \\
\hline \multicolumn{4}{|l|}{ Extraction Method: Principal Component Analysis. } \\
\hline Rotation Method: Varimax with Kaiser Normalization & & & \\
\hline
\end{tabular}


science conduct medical research. Medical research is a dummy variable ( $1=$ conducts medical research). Because research indicates that men scientists and engineers are more likely than women to apply for patents (Azoulay et al., 2007), we control for sex with a dummy variable $(1=$ male $)$.

Finally, since prior literature indicates that R\&D funds are positively related to university patent performance (Coupe, 2003) and industry funding may drive scientists from curiosity-oriented research towards patenting and commercialization activities (Agrawal and Henderson, 2002; Strandburg, 2005), we control for the level of government funding and industry funding. Government funding and industry funding are measured as the percentage of research funding that the respondent reports receiving from each source. The reliability of all constructed study variables and questionnaire items are presented in Appendix 1. Tables 2 and 3 list the descriptive statistics and the correlations for the study variables, respectively.

\section{Method}

Because our dependent variable is a count measure - number of patents awarded - either Poisson or negative binomial maximum likelihood methods are more suitable estimation methods than ordinary least squares regression (Cameron and Trivedi, 1998). While Poisson regression contains a strong assumption that there is no overdispersion of the dependent variable, negative binomial regression adjusts for inflated variance and is best used when the dependent variable is overdispersed (Hilbe, 2007). Additionally, when the dependent count variable includes excess zeros, it may be more appropriate to use a zero-inflated negative binomial estimation (ZINB) (Yau et al., 2003; Hilbe, 2007). ZINB regression estimation is generally used for common or natural situations in which there are high numbers of zeros in the count distribution and is often used in research on patenting because the dependent variable has a large proportion of zeros - scientists and engineers who have never been awarded a patent (Azagra-Caro et al., 2006; Carayol, 2007; Stephan et al. 2007).

The ZINB estimation has two parts that account for excess zeros. One part is binary. A logistic or probit model is used to predict the likelihood of zero count; in this case it is the likelihood that the individual does not have a patent. The second part predicts the likelihood of a count greater than zero based on a negative binomial distribution, for each scientist to engineer $i$. The ZINB regression model assumes that events (patents) $Y=Y_{1}, Y_{2}, \ldots, Y_{n}$ are independent, while the expected value of $Y$ patents for any $i$ scientists or engineer is stated as:

$E\left(Y_{i}\right)=\lambda_{i}=\exp \left(X_{i} \beta\right)$

where $\lambda$ represents the expected value, $X_{i}$ is a vector of variables predicting patenting activity and $\beta$ is the vector of maximum likelihood estimated regression coefficients (Greene, 2003). The vector of variables used here includes: faculty rank, publishing, openscience attitudes, university royalty policy, department patenting incentives, department patenting

\begin{tabular}{|c|c|c|c|c|c|c|c|c|c|c|c|c|c|c|c|}
\hline \multirow[b]{2}{*}{ Variables } & \multicolumn{5}{|c|}{ Total } & \multicolumn{5}{|c|}{$\begin{array}{l}\text { Scientists with one or more } \\
\text { patents }\end{array}$} & \multicolumn{5}{|c|}{ Scientists with zero patents } \\
\hline & Obs & Mean & SD & Min & $\operatorname{Max}$ & Obs & Mean & SD & Min & Max & Obs & Mean & SD & Min & $\operatorname{Max}$ \\
\hline Number of Patents & 1363 & 4.27 & 10.27 & 0 & 157 & 739 & 7.87 & 12.90 & 1 & 157 & 624 & 0.00 & 0.00 & 0 & 0 \\
\hline Assistant Professor & 1379 & 0.18 & 0.39 & 0 & 1 & 755 & 0.06 & 0.23 & 0 & 1 & 624 & 0.34 & 0.47 & 0 & 1 \\
\hline Associate Professor & 1379 & 0.22 & 0.41 & 0 & 1 & 755 & 0.16 & 0.37 & 0 & 1 & 624 & 0.28 & 0.45 & 0 & 1 \\
\hline Full Professor & 1379 & 0.60 & 0.49 & 0 & 1 & 755 & 0.78 & 0.41 & 0 & 1 & 624 & 0.38 & 0.48 & 0 & 1 \\
\hline Publishing & 1308 & 13.02 & 13.42 & 0 & 176 & 711 & 15.78 & 15.64 & 0 & 176 & 597 & 9.73 & 9.16 & 0 & 79 \\
\hline Open Science Attitude & 1344 & 8.85 & 2.74 & 4 & 16 & 744 & 8.12 & 2.60 & 4 & 16 & 600 & 9.75 & 2.63 & 4 & 16 \\
\hline University Royalty Policy & 1342 & 0.81 & 0.39 & 0 & 1 & 733 & 0.93 & 0.25 & 0 & 1 & 609 & 0.65 & 0.48 & 0 & 1 \\
\hline Department Incentives & 1324 & 3.32 & 1.40 & 2 & 8 & 725 & 3.39 & 1.42 & 2 & 8 & 599 & 3.24 & 1.37 & 2 & 8 \\
\hline Department Assistance & 1178 & 0.23 & 0.42 & 0 & 1 & 654 & 0.21 & 0.41 & 0 & 1 & 524 & 0.26 & 0.44 & 0 & 1 \\
\hline TTO Professionalism & 1072 & 0.00 & 1.00 & -2.69 & 2.15 & 676 & -0.02 & 1.02 & -2.41 & 2.13 & 396 & 0.04 & 0.97 & -2.69 & 2.15 \\
\hline TTO Barriers & 1072 & 0.00 & 1.00 & -3.04 & 2.46 & 676 & -0.06 & 0.98 & -2.49 & 2.45 & 396 & 0.11 & 1.03 & -3.04 & 2.46 \\
\hline TTO Profit Drive & 1072 & 0.00 & 1.00 & -2.05 & 2.57 & 676 & -0.12 & 1.04 & -2.05 & 2.57 & 396 & 0.21 & 0.89 & -1.64 & 2.54 \\
\hline Patenting Experience & 1338 & 0.16 & 0.37 & 0 & 1 & 724 & 0.16 & 0.37 & 0 & 1 & 614 & 0.16 & 0.37 & 0 & 1 \\
\hline Engineering & 1379 & 0.33 & 0.47 & 0 & 1 & 755 & 0.33 & 0.47 & 0 & 1 & 624 & 0.33 & 0.47 & 0 & 1 \\
\hline Biological Sciences & 1379 & 0.27 & 0.44 & 0 & 1 & 755 & 0.26 & 0.44 & 0 & 1 & 624 & 0.29 & 0.45 & 0 & 1 \\
\hline Chemistry & 1379 & 0.15 & 0.36 & 0 & 1 & 755 & 0.14 & 0.35 & 0 & 1 & 624 & 0.16 & 0.37 & 0 & 1 \\
\hline Computer Science & 1379 & 0.03 & 0.19 & 0 & 1 & 755 & 0.03 & 0.16 & 0 & 1 & 624 & 0.05 & 0.21 & 0 & 1 \\
\hline Medical Sciences & 1379 & 0.13 & 0.34 & 0 & 1 & 755 & 0.15 & 0.36 & 0 & 1 & 624 & 0.11 & 0.31 & 0 & 1 \\
\hline Physics & 1379 & 0.06 & 0.24 & 0 & 1 & 755 & 0.08 & 0.27 & 0 & 1 & 624 & 0.04 & 0.19 & 0 & 1 \\
\hline Other & 1379 & 0.03 & 0.17 & 0 & 1 & 755 & 0.02 & 0.14 & 0 & 1 & 624 & 0.04 & 0.20 & 0 & 1 \\
\hline Medical Research & 1334 & 0.50 & 0.50 & 0 & 1 & 731 & 0.58 & 0.49 & 0 & 1 & 603 & 0.41 & 0.49 & 0 & 1 \\
\hline Male & 1377 & 0.82 & 0.38 & 0 & 1 & 753 & 0.89 & 0.31 & 0 & 1 & 624 & 0.74 & 0.44 & 0 & 1 \\
\hline Government Funding & 1294 & 62.30 & 31.27 & 0 & 100 & 705 & 63.26 & 30.26 & 0 & 100 & 589 & 61.15 & 32.42 & 0 & 100 \\
\hline Industry Funding & 1294 & 11.30 & 19.41 & 0 & 100 & 705 & 14.50 & 21.18 & 0 & 100 & 589 & 7.47 & 16.26 & 0 & 100 \\
\hline
\end{tabular}






assistance, TTO professionalism, TTO barriers, TTO profit drive, patenting experience, field of science, medical research, sex, government funding, and industry funding. The two-part probability of observing a specific patent count $Y$ is computed as:

$\mathrm{p}_{\mathrm{i}}+\left(1-\mathrm{p}_{\mathrm{i}}\right)\left[\frac{1 / \alpha}{(1 / \alpha)+\lambda_{i}}\right]^{\frac{1}{\alpha}}$,

$Y_{i}=0$ with probability

$Y_{i}=y$

$\left(1-p_{i}\right)\left[\frac{\mathrm{r}((1 / \alpha)+y) u_{i}^{1 / \alpha}\left(1-\mu_{i}\right)^{y}}{\mathrm{r}(1 / \alpha) y !}\right]$,

with probability

$Y=1,2, \ldots$

where $\alpha$ is the dispersion parameter, $\mu_{i}=(1 / \alpha) /\left[(1 / \alpha)+\lambda_{i}\right]$, and $\lambda$ represents gamma model of the Poisson probability distribution (Lee and Mannering, 2002; Stephan et al., 2007).
To determine whether the ZINB model was appropriate, we conducted two tests using Stata version 10.1. First, the Poisson goodness-of-fit test was used to determine whether the dependent variable was overdispersed. Based on our results, we reject the null hypothesis that the mean is equal to the variance, characteristic of a Poisson distribution $(p<0.001)$, and find in favor of using negative binomial regression. Second, the Vuong test was conducted to determine whether the distribution requires a zero-inflated model (Greene, 1994). A significant $\mathrm{v}$ statistic $(\mathrm{v}=3.63, \mathrm{p}<0.001)$ indicates that the ZINB model is preferred to the standard negative binomial regression.

\section{Results}

Table 4 presents the results of the regression estimations. The first column shows the logistic estimation results for zero-counts with control variables only. The second column displays the negative binomial estimation results for non-zero counts with the baseline model. The third column contains logistic estimation results for zero-counts with control variables and the variables of interest. The fourth column 




\begin{tabular}{|c|c|c|c|c|c|c|}
\hline & \multicolumn{6}{|c|}{ Full model } \\
\hline & \multicolumn{3}{|c|}{$\begin{array}{l}\text { Prediction of Zero Patents } \\
\text { (Logistic Regression) }\end{array}$} & \multicolumn{3}{|c|}{$\begin{array}{l}\text { Prediction of One or More Patents } \\
\text { (Negative Binomial Regression) }\end{array}$} \\
\hline & Coeff. & SE & OR & Coeff. & SE & IRR \\
\hline Assistant Professor ${ }^{a}$ & 3.17 & $0.72^{* * *}$ & 23.87 & -1.58 & $0.31^{* * *}$ & 0.21 \\
\hline Associate Professor & 0.37 & 0.59 & 1.44 & -0.91 & $0.15^{* * *}$ & 0.40 \\
\hline Publishing & -0.14 & 0.05 ** & 0.87 & 0.01 & 0.00 * & 1.01 \\
\hline Open Science Attitude & 0.15 & 0.11 & 1.16 & -0.12 & $0.02 * * *$ & 0.89 \\
\hline University Royalty Policy & -3.28 & $0.89^{* * *}$ & 0.04 & 0.27 & 0.29 & 1.31 \\
\hline Department Incentives & 0.28 & 0.20 & 1.32 & 0.09 & 0.04 * & 1.09 \\
\hline Department Assistance & 0.87 & 0.63 & 2.38 & -0.04 & 0.14 & 0.96 \\
\hline TTO Professionalism & 0.25 & 0.26 & 1.28 & 0.00 & 0.06 & 1.00 \\
\hline TTO Barriers & 0.75 & 0.36 * & 2.13 & 0.01 & 0.06 & 1.01 \\
\hline TTO Profit Drive & 0.88 & 0.31 & 2.41 & 0.02 & 0.06 & 1.02 \\
\hline Patenting Experience & 1.33 & 0.66 * & 3.78 & 0.44 & $0.15^{* *}$ & 1.56 \\
\hline Biological Sciences $^{\mathrm{b}}$ & 1.34 & $0.78+$ & 3.83 & 0.03 & 0.16 & 1.03 \\
\hline Chemistry & 1.28 & $0.76 \dagger$ & 3.60 & 0.72 & $0.18^{* * *}$ & 2.05 \\
\hline Computer Science & -2.34 & 3.21 & 0.10 & -1.00 & 0.34 ** & 0.37 \\
\hline Medical Sciences & -6.72 & 4.63 & 0.00 & -0.31 & $0.18+$ & 0.73 \\
\hline Physics & -3.71 & 4.70 & 0.02 & 0.21 & 0.20 & 1.23 \\
\hline Other & -12.07 & 775.12 & 0.00 & -1.51 & $0.47^{* *}$ & 0.22 \\
\hline Medical Research & -0.97 & $0.57 \dagger$ & 0.38 & 0.48 & $0.13^{* * *}$ & 1.62 \\
\hline Male & 0.87 & 0.73 & 2.40 & 0.67 & $0.17^{* \star *}$ & 1.95 \\
\hline Government Funding & 0.01 & 0.01 & 1.01 & 0.00 & 0.00 & 1.00 \\
\hline Industry Funding & 0.00 & 0.02 & 1.00 & 0.01 & $0.00^{* * *}$ & 1.01 \\
\hline Constant & -2.53 & 1.64 & & 0.80 & $0.46 \dagger$ & \\
\hline $\mathbf{N}$ & 829 & & & 829 & & \\
\hline LR chi2 & 234.47 & *** & & $234.47^{* * *}$ & & \\
\hline Log Likelihood & -1793.97 & & & -1793.97 & & \\
\hline
\end{tabular}

Notes: $\quad+p<0.1 ;{ }^{*} p<0.05 ;{ }^{* *} p<0.01 ;{ }^{* * *} p<0.001$ a Reference category is Full Professor, b Reference category is Engineering, c OR refers to odds ratio; IRR refers to incidence rate ratios

presents the negative binomial estimation results for non-zero counts with the full model. Overall, inclusion of the individual and organizational variables of interest notably improves the model fit to our data. The baseline model produces chi-square $\chi^{2}(11)=$ $137.49, \mathrm{p}<0.001$. The full model generates $\chi^{2}(21)$ 
$=234.47, \mathrm{p}<0.001$. According to the chi-square goodness-of-fit test, the full model significantly increases the model fit, with $\Delta \chi^{2}(10)=96.98$, $\mathrm{p}<0.001$. In this section, we present the results in order of the hypotheses and then discuss the control variables.

The first three hypotheses predicted significant relationships between individual characteristics (academic rank, publishing, open-science attitudes) and the likelihood of having no patent and reporting multiple patents. We find strong support for the first hypothesis that senior scientists compared to junior scientists are significantly more likely to patent. The logistic model indicates that assistant professors are more likely to have zero patents than full professors $(\mathrm{p}<0.001)$. The negative binomial model estimations also indicate that assistant professors and associate professors are significantly likely to produce fewer patents than full professors $(\mathrm{p}<0.001)$. These findings support previous research (Thursby et al., 2007) that senior scientists are more likely to patent, possibly because of job security, cumulative knowledge, and prior experience.

The logistic model estimation demonstrates support for the second hypothesis. Results show that scientists who publish less are more likely to not have a patent. Specifically a one-unit decrease in the number of publications results in a 0.13 increase in the odds of not having a patent $(\mathrm{p}<0.01)$. Likewise, publishing is a significant predictor of reporting a greater number of patents $(p<0.05)$. Scientists who report increased peer-reviewed publications are significantly likely to report more patents. These findings imply that patenting and publishing should be regarded as complementary activities, rather than substitutive activities that compete for a researcher's time and resources. ${ }^{5}$

The estimation results partially support our third hypothesis. The negative binomial estimation indicates that scientists who report stronger openscience attitudes report significantly fewer patents than those who do not have strong open-science attitudes $(p<0.001)$. However, logistic results show no evidence that scientists with stronger open-science attitudes are more likely to have zero patents. These findings may indicate that the perceived tension between IP protection and traditional open-science norms is relevant only after scientists begin to patent.

Overall, we find mixed support for the hypothesized relationships between organizational factors and patenting production. First, there is some support for our fourth hypothesis that scientists who work in an environment that values entrepreneurial behavior will be more likely to produce a patent. The logistic estimation shows that scientists without knowledge of the university royalty policy are more likely to have zero patents $(p<0.001)$. The odds that a scientist without knowledge of university royalty policy has zero patents are 1.96 times higher than the odds that a scientist who has knowledge of the university royalty policy will not have a patent.
However, the negative binomial results find no significant relationship between university royalty policy and an increased number of patents, indicating that once a scientist patents, a university royalty policy does not induce scientists to patent more or less. The results indicate that a university's patent policy may remove initial barriers to patenting by signaling attention to the potential monetary benefits of patenting, but it does not necessarily provide incentives for continued patent production.

Department patenting incentives is significantly related to an increase in the quantity of patents reported. Scientists who perceive stronger department patenting incentives are significantly more likely to produce multiple patents. Departments that recognize and value the scientific merits of patents and encourage faculty patenting activities may motivate scientists to pursue more patentable inventions and thereby increase patenting outcomes. The logistic estimation indicates that a lack of department incentives is not a significant predictor of producing zero patents, meaning that department incentives are important determinants for producing a number of patents, but do not distinguish patenters from non-patenters.

Contrary to our expectation, department patenting assistance has no notable influence on either the likelihood of having a patent or on the number of patents produced. Our speculation is that the provision of administrative assistance at the department level is minimally effective because the TTO is the primary service organization that processes patenting paperwork.

We find that there are significant relationships between the perceived effectiveness of the university's TTO and individual patenting production (H5). The estimations indicate the importance of the TTO with both expected and unexpected results. On the one hand, none of the TTO measures are significant in the negative binomial regression (the production of multiple patents). This probably indicates that the quantity of patents scientists and engineers produce is not primarily determined by the university TTO, or at least there is no association between scientists' perceptions of the TTO and their patenting production levels. On the other hand, we find that scientists who perceive the TTO as highly bureaucratic and that the TTO is 'only interested in certain fields or disciplines, especially those that have generated royalties' are more likely to report having no patents $(\mathrm{p}<0.05)$. This result aligns with prior studies arguing that university bureaucracy is a barrier to patenting activities (Blumenthal et al., 1996; Siegel et al., 2003). However, the result also moves beyond prior research by showing that barriers created by TTOs may be limited to patent entry, rather than patent productivity.

The logistic regression indicates that perceiving a strong TTO profit drive is positively associated with the probability of not having a patent $(p<0.01)$. This finding indicates that when the TTO more 
actively pursues profitable technology transfer opportunities, it may be more selective about patent filings and thereby reduce the likelihood that a scientist holds a patent. Again we see that TTO policies and behavior may affect entry of scientists into patenting, but are not significantly related to the number of patents produced.

We also find significant relationships between our dependent variable and the following control variables: patenting experience, field of science, medical research, sex, and industry funding. The results indicate that patenting experience as a PhD student contributes to the likelihood that a respondent will not have a patent at the current-employment university $(p<0.05)$. However, patenting experience during one's $\mathrm{PhD}$ training is significantly related to reporting multiple patents $(\mathrm{p}<0.01)$, indicating that past experiences have a positive effect on patent production. The results imply that people who have patenting experiences as $\mathrm{PhD}$ students diverge into two groups: those who continue to patent and those who do not. It is possible that for the first group $\mathrm{PhD}$ training prepares scientists and engineers to produce patents while for the second group $\mathrm{PhD}$ training discourages further patent activity. Further work should examine this divergence in greater detail.

We see that biologists and chemists are weakly associated with the probability of zero patents $(\mathrm{p}<0.1)$, indicating that field of science may not necessarily be a strong determinant of entry into patenting. However, the number of patents produced significantly varies across the fields. As compared to engineers, chemists produce more patents while computer scientists and researchers in the medical sciences generate fewer patents. These findings support previous research that indicates that engineers tend to have more patent applications (Stephan et al., 2007) most likely because of integrating basic research and application (Ambos et al., 2008). Prior research also finds that computer scientists produce fewer patents, most likely because they are pursuing copyrights (Stephan et al., 2007). Because the ZINB estimation shows that the coefficient on physicists is not significant, our findings also support prior work that physicists engage in patenting activities at the same levels as engineers (Meyer-Krahmer and Schmoch, 1998; Azagra-Caro et al., 2003). Chemists are more likely than engineers to have no patents, but also more likely to produce a greater number of patents than engineers. We also find that scientists who conduct medical research are less likely to have zero patents $(\mathrm{p}<0.1)$ and more likely to produce multiple patents $(\mathrm{p}<0.001)$.

We find that men scientists are significantly more likely to have an increased number of patents as compared to women scientists $(p<0.001)$. Finally, increased industry funding is related to greater number of patents awarded $(p<0.001)$. As suggested by the literature, scientists and engineers who are more closely connected with industry will be involved in a greater proportion of applied research projects and thus more likely to have patentable research outcomes (Agrawal and Henderson, 2002). Alternative$1 y$, industry involvement may raise awareness about patenting or create greater university interest in developing mechanisms to track and delineate its IP rights as distinct from that of the industry funders.

There are some limitations to the generalizability of these findings. First, our sample of patenters includes only the population of 2006 university patenters; it is possible that individuals who patent in different years would have different responses to the survey. Additionally, the analysis focuses inventors, not collaborators. Thus, it is possible that the sample is biased towards more senior researchers. Nevertheless, the data are drawn from faculty across the USA at multiple universities, thus providing variation across and within state and university and adding robustness to the models. Third, because these are cross-sectional data from a single survey, we cannot make causal claims about the relationships. For that reason, we emphasize association between studied factors and individual production of university patents.

\section{Conclusion}

This study improves our understanding of academic patenting activities by looking inside the black box of university patenting. Since the passage of BayhDole Act in 1980, US universities have pursued several initiatives to encourage patenting including the creation of TTOs and the development of internal patent policies. For instance, in 1980, only 25 US universities had TTOs, but by 1990 there were more than 200 (Bozeman, 2000: 635). The rapid diffusion of TTOs can be regarded as a university response to the policy change; however, the presence of structures in organizations does not guarantee adoption of new initiatives at the individual level (Bercovitz and Feldman, 2008). TTOs do not necessarily affect individual patent productivity. As importantly, they are not the only mechanism that could lead to patent production changes at universities. This research investigates the ways in which university- and department-level factors, as well as individual factors, result in the production of patents by individual scientists and engineers. This section discusses the implications of the findings for our further understanding of these relationships and for academic patent policy.

Three individual characteristics examined in this study - seniority, publishing, and open-science attitudes - are strongly related to the likelihood of having multiple patents. Our findings help to clarify the theoretical debate between the life-cycle model and the path-dependence argument on scientists' career development. Our analysis indicates that full professors who achieve a certain level of stability in their career trajectory are more likely to engage in patenting activities than assistant professors. And 


\section{Our analysis indicates that full professors who achieve a certain level of stability in their career trajectory are more likely to engage in patenting activities than assistant professors}

associate professors who are in midcareer are less likely than full professors to patent, most likely because the full professor has more time, resources, and capacity to dedicate to patenting. The findings indicate that incentives targeted to senior faculty might be more effective than those targeting junior faculty. The propensity of senior faculty to patent may derive from the fact that senior faculty have higher capacity and resources to produce knowledge that is both publishable and patentable. Additionally, senior faculty may be under less pressure to pursue job security and may be more able to engage in patenting activities. For universities that would like to encourage patenting among junior faculty, it might be beneficial to encourage patenting activities through the promotion and tenure system.

Second, patenting activities do not substitute publishing activities. We find a positive association between the two activities, suggesting that publishing tends to complement the knowledge and skills that scientists need to produce inventions and to receive awards on patents and vice versa. Third, our findings indicate that university scientists and engineers who favor open science and perceive IP protection as conflicting with traditional open-science norms tend to produce fewer patents, but they are not necessarily dissuaded from seeking a patent. Open-science norms do not create barriers to entry, but they do reduce the enthusiasm for continued patent production over the career.

Universities, departments, and TTOs that continually push patenting opportunities to scientists with strong open-science attitudes, must recognize that, on average, reluctance to produce more patents relates to intrinsic motivations and deep-seated perspectives on the model of knowledge production. In some cases, scientists recognize that the knowledge production model proposed by Griliches (1990) is correct, arguing that patents are an outcome of knowledge production. However, these results show that one reason why it is fundamentally an imperfect indicator relates to the fact that scientists do not agree on the model; simply put, some scientists do not believe that patents are a valid knowledge outcome and therefore do not engage in producing that outcome.

In addition to individual characteristics, organizational factors help explain patenting activity of academic scientists and engineers. Similar to
Renault (2006), our analysis points to the importance of department-level incentive and encouragement mechanisms that foster institutionalization of a favorable patenting environment, suggesting that the third mission can be cultivated and embedded into the academic environment by modifying the way faculty are recognized and promoted. We find that a favorable department reward system that promotes patenting encourages scientists and engineers to engage in more research that is both publishable and patentable. Such incentives also more explicitly integrate patenting within an organizationally validated knowledge production model.

On the other hand, university-level organizational factors are also significantly related to the likelihood of scientists and engineers not having a patent, but they have no notable impact on higher individuallevel patent production. Universities that have no recognized royalty policy, high perceived TTO barriers, or a strong TTO profit drive, create barriers for scientists to produce their first patent. For policymakers and university managers who aim to encourage patenting activities at universities, it is important both to design desirable university-level policies and department-level incentive systems regarding patenting and to educate and disseminate patenting information to scientists. Consistent with prior studies (Thursby and Kemp, 2002; Moutinho et al., 2007), we find that a bureaucratic TTO may be a barrier to fostering an attempt to patent, especially for those who had no previous involvement in patenting (Moutinho et al., 2007).

Our analysis also shows that perceptions that the TTO is profit-driven tend to increase the likelihood of not having a patent. It is reasonable to anticipate that profit-driven TTOs may tend not to file a patent unless they see the prospect of economic returns from the invention. When TTOs are more selective and discerning about committing resources to patenting, they may be doing so to reduce costs and increase efficiencies within their own office, since many TTOs have limited budgets to dedicate to the investment in pursuing patents and licenses. However, TTOs are serving as gatekeepers that choose knowledge production units presenting an inconsistent knowledge production model for scientists. This approach risks limiting or reducing a scientist's initiative and motivation; it communicates one type of knowledge production model for the TTO and a different one for scientists. As boundary organizations between individual scientists, universities, the USTPO, and potential licensees, TTOs may be operating under a different set of constraints and incentives from the scientists they aim to support. In sum, the TTOs' profit drive - a requirement for their own success and survival at the university - may be incompatible with encouraging academic scientists to patent.

On the whole, the individual and organizational effects identified in this analysis show that universitylevel factors create an environment for patenting, while patenting production is mostly induced by 
individual characteristics and department-level incentives. The presence of university royalty policies and a supportive TTO remove potential barriers to patenting, but they have limited ability to motivate continued patenting activities, especially when they promote a knowledge-production model that is inconsistent with the views of academic scientists.
Scientists may patent more when they perceive that organizations at the university and department levels promote a consistent knowledge production model. That said, organizational efforts still may not be enough as individual level open-science attitudes, prior experience, and other factors not examined here intervene.

\section{Appendix 1. The construct of variables and reliability}



\section{Notes}

1. Non-patenters were identified based on two USPTO online databases: PATFT and AppFT. PATFT includes information of issued US patents since 1790. AppFT includes information of US patent applications filed since March 2001. For patents issued after 1976, PATFT provides the full-text information (e.g. issue date, patent title, abstract, inventor's name, assignee's name, patent class, and claims).

2. This measure only includes patents for which the respondent is the 'inventor' defined as 'one who contributes to the conception of an invention' (USPTO). It does not include patents 'collaborators'.

3. This question was excerpted from a 2004-2005 survey of academic researchers developed by Barry Bozeman's Research Value Mapping Program.

4. This measure of patenting culture and norms stresses whether or not faculty know about the patent policy as opposed to whether the policy actually exists. It is certainly possible that a university has a royalty policy, but respondents do not know about it, or vice versa. 
5. It is possible that the publishing coefficients might be overestimated because seniority may be correlated with both patenting and publishing activities. We have run separate models for different academic ranks and find that the coefficient for publishing is lower for higher-rank than for lower-rank estimations. While this does not eliminate the possibility of overestimation, it indicates that overestimation as a result of correlation with seniority is not a fundamental issue for the estimation.

\section{References}

Agrawal, A and R Henderson 2002. Putting patents in context: exploring knowledge transfer from MIT. Management Science, 48(1), 44-60.

Ambos, T C, K Makela, J Birkinshaw and P D'Este 2008. When does university research get commercialized? Creating ambidexterity in research institutions. Journal of Management Studies, 45(8), 1424-1447.

American Association for Public Opinion Research 2008. Standard Definitions: Final Dispositions of Case Codes and Outcome Rates for Surveys, 5th edn. Lenexa, Kansas: American Association for Public Opinion Research.

Audretsch, D B and D Kayalar-Erdem 2005. Determinants of scientist entrepreneurship: an integrative research agenda. In Handbook of Entrepreneurship Research: Disciplinary Perspectives, eds S A Alvarez, R Agarwal and O Sorenson. New York, NY: Springer.

Azagra-Caro, J M, N Carayol and P Llerena 2003. Contractual Funding and University Patents: From Analysis to a Case Study. Paper presented at the DRUID Summer Conference 2003 on Creating, Sharing and Transferring Knowledge.

Azagra-Caro, J M, N Carayol and P Llerena 2006. Patent production at a European research university: exploratory evidence at the laboratory level. Journal of Technology Transfer, 31(2), 257-268.

Azagra-Caro, J M, F Archontakis and A Yegros-Yegros 2007. In which regions do universities patent and publish more? Scientometrics, 70(2), 251-266.

Azoulay, P, W Ding and T Stuart 2007. The determinants of faculty patenting behavior: demographics or opportunities? Journal of Economic Behavior and Organization, 63(4), 599-623.

Baldini, N, R Grimaldi and M Sobrero 2005. Motivations and incentives for patenting within universities: a survey of Italian inventors. Academy of Management Proceedings, A1-A6.

Baldini, N, R Grimaldi and M Sobrero 2007. To patent or not to patent? A survey of Italian inventors on motivations, incentives, and obstacles to university patenting. Scientometrics, 70(2), 333-354.

Bercovitz, J and M Feldman 2008. Academic entrepreneurs: organizational change at the individual level. Organization Science, 19(1), 69-89.

Bercovitz, J, M Feldman, I Feller and R Burton 2001. Organizational structure as a determinant of academic patent and licensing behavior: an exploratory study of Duke, Johns Hopkins, and Pennsylvania State Universities. Journal of Technology Transfer, 26(1-2), 21-35.

Blumenthal, D, E G Campbell and N Causino 1996. Participation of life-science faculty in research relationships with industry. New England Journal of Medicine, 335, 1734-1739.

Bozeman, B 2000. Technology transfer and public policy: a review of research and theory. Research Policy, 29(4-5), 627-655.

Brockhaus, R H and P S Horwitz 2002. The psychology of the entrepreneur. In Entrepreneurship: Critical Perspectives on Business and Management (Vol. 2), eds N F Krueger. New York, NY: Routledge.

Buenstorf, G 2009. Is commercialization good or bad for science? Individual-level evidence from the Max Planck Society. Research Policy, 38(2), 281-292.

Bush, V 1945. Science: the Endless Frontier. Washington: US Government Printing Office.

Cameron, A C and P K Trivedi 1998. Regression Analysis of Count Data. Cambridge University Press.

Carayol, N 2007. Academic incentives, research organization and patenting at a large French university. Economics of Innovation and New Technology, 16(2), 119-138.

Coriat, B and F Orsi 2002. Establishing a new intellectual property rights regime in the United States: origins, content and problems. Research Policy, 31(8-9), 1491-1507.

Coupe, T 2003. Science is golden: academic R\&D and university patents. Journal of Technology Transfer, 28(1), 31-46.

Dai, Y, D Popp and S Bretschneider 2005. Institutions and intellectual property: the influence of institutional forces on university patenting. Journal of Policy Analysis and Management, 24(3), 579-598.

Dasgupta, P and P A David 1994. Toward a new economics of science. Research Policy, 23(5), 487-521.

David, P A 2004. Can 'open science' be protected from the evolving regime of IPR protections? Journal of Institutional and Theoretical Economics, 160(1), 9-34.

Etzkowitz, H 2008. The Triple Helix: University-IndustryGovernment Innovation in Action. New York, NY: Routledge.

Fabrizio, K R and A Di Minin 2008. Commercializing the laboratory: faculty patenting and the open science environment. Research Policy, 37(5), 914-931.

Feldman, M, I Feller, J Bercovitz and R Burton 2002. Equity and the technology transfer strategies of American research universities. Management Science, 48(1), 105-121.

Franzioni, Chiara 2009. Do scientists get fundamental research ideas by solving practical problems? Industrial and Corporate Change. doi: 10.1093/icc/dtp021.

Friedman, J and J Silberman 2003. University technology transfer: do incentives, management, and location matter? Journal of Technology Transfer, 28(1), 17-30.

Geuna, A and L Nesta 2006. University patenting and its effects on academic research: the emerging European evidence. Research Policy, 35(6), 790-807.

Gioia, D A, J Thomas, S Clark and K Chittipeddi 1994. Symbolism and strategic change in academia: the dynamics of sensemaking and influence. Organization Science, 5(3), 363-383.

Greene, W 1994. Accounting for Excess Zeros and Sample Selection in Poisson and Negative Binomial Regression Models. NYU Working Paper No. EC-94-10.

Greene, W 2003. Econometric Analysis, 5th edn. Englewood Cliffs: Prentice-Hall.

Griliches, Zvi 1990. Patent statistics as economic indicators: a survey. Journal of Economic Literature, 28, 1661-1707.

Henderson, R, A B Jaffe and M Trajtenberg 1998. Universities as a source of commercial technology: a detailed analysis of university patenting, 1965-1988. Review of Economics and Statistics, 80(1), 119-127.

Hilbe, J M 2007. Negative Binomial Regression. New York: Cambridge University Press.

Jensen, R A, J G Thursby and M C Thursby 2003. Disclosure and licensing of university inventions: 'The best we can do with the $\mathrm{s}^{* *} \mathrm{t}$ we get to work with'. International Journal of Industrial Organization, 21(9), 1271.

Lach, S and M Schankerman 2008. Incentives and invention in universities. RAND Journal of Economics, 39(2), 403-433.

Lee, $\mathrm{J}$ and $\mathrm{F}$ Mannering 2002. Impact of roadside features on the frequency and severity of run-off-roadway accidents: an empirical analysis. Accident Analysis and Prevention, 34(2), 149-161.

Levin, S G and P E Stephan 1991. Research productivity over the life cycle: evidence for academic scientists. American Economic Review, 81(1), 114-132.

Louis, K S, David Blumenthal, M E Gluck and M A Soto 1989. Entrepreneurs in academe: an exploration of behaviors among life scientists. Administrative Science Quarterly, 34(1), 110-313.

Mazzoleni, R and R R Nelson 1998. The benefits and costs of strong patent protection: a contribution to the current debate. Research Policy, 27(3), 273-284.

Merton, R 1942 . Science and technology in a democratic order. Journal of Legal and Political Sociology, 1, 115-126.

Meyer-Krahmer, F and U Schmoch 1998. Science-based technologies: university-industry interactions in four fields. Research Policy, 27(8), 835-851.

Moutinho, P S F, M Fontes and M M Godinho 2007. Do individual factors matter? A survey of scientists' patenting in Portuguese public research organizations. Scientometrics, 70(2), 355-377.

Mowery, D C and B N Sampat 2005. Universities in national innovation systems. In The Oxford Handbook of Innovation, eds $\mathrm{J}$ Fagerberg, D C Mowery and R R Nelson. New York, NY: Oxford University Press, Inc.

Mowery, D C and A A Ziedonis 2002. Academic patent quality and quantity before and after the Bayh-Dole act in the United States. Research Policy, 31(3), 399-418.

Mowery, D C, R R Nelson, B N Sampat and A A Ziedonis 2001. 
The growth of patenting and licensing by U.S. universities: an assessment of the effects of the Bayh-Dole act of 1980. Research Policy, 30(1), 99-119.

Murray, F and S Stern 2007. Do formal intellectual property rights hinder the free flow of scientific knowledge? An empirical test of the anti-commons hypothesis. Journal of Economic Behavior and Organization, 63(4), 648-687.

Ostrom, E and C Hess 2005. A framework for analyzing the knowledge commons. In Understanding Knowledge as a Commons: from Theory to Practice, eds C Hess and E Ostrom. Cambridge, MA: MIT Press.

Owen-Smith, J and W W Powell 2001. To patent or not: faculty decisions and institutional success at technology transfer. Journal of Technology Transfer, 26(1-2), 99-114.

Powell, W W and J Owen-Smith 1998. Universities and the market for intellectual property in the life sciences. Journal of Policy Analysis and Management, 17(2), 253-277.

Renault, C S 2006. Academic capitalism and university incentives for faculty entrepreneurship. Journal of Technology Transfer, 31, 227-239.

Rothaermel, F T, S D Agung and L Jiang 2007. University entrepreneurship: a taxonomy of the literature. Industrial and Corporate Change, 16(4), 691-791.

Salter, A J and B R Martin 2001. The economic benefits of publicly funded basic research: a critical review. Research Policy, 30(3), 509-532.

Sanz-Menéndez, L and L Cruz-Castro 2003. Coping with environmental pressures: public research organisations responses to funding crises. Research Policy, 32(8), 1293-1308.

Shane, Scott 2000. Prior knowledge and the discovery of entrepreneurial opportunities. Organization Science, 11(4), 448-469.

Siegel, D S, D Waldman and A Link 2003. Assessing the impact of organizational practices on the relative productivity of university technology transfer offices: an exploratory study. Research Policy, 32(1), 27-48.

Sine, W D, S Shane and D D Gregorio 2003. The halo effect and technology licensing: the influence of institutional prestige on the licensing of university inventions. Management Science, 49(4), 478-496.

Stephan, P E, S Gurmu, A J Sumell and G Black 2007. Who's patenting in the university? Evidence from the survey of doctorate recipients. Economics of Innovation and New Technology, 16(2), 71-99.

Strandburg, $\mathrm{K}$ J 2005. Curiosity-driven research and university technology transfer. In University Entrepreneurship and Technology Transfer: Process, Design, and Intellectual Property, eds G D Libecap. San Diego, CA: ELSEVIER Inc.

Thursby, J G and S Kemp 2002. Growth and productive efficiency of university intellectual property licensing. Research Policy, 31(1), 109-124.

Thursby, J G and M C Thursby 2002. Who is selling the ivory tower? Sources of growth in university licensing. Management Science, 48(1), 90-104.

Thursby, J G, R Jensen and M Thursby 2001. Objectives, characteristics and outcomes of university licensing: a survey of major U.S. universities. Journal of Technology Transfer, 26(1-2), 59-72.

Thursby, M, J Thursby and S Gupta-Mukherjee 2007. Are there real effects of licensing on academic research? A life cycle view. Journal of Economic Behavior and Organization, 63(4), $577-598$.

United States Patent and Trademark Office 2010. Glossary. Available at $<\mathrm{http}: / /$ www.uspto.gov/>, last accessed 26 February 2010.

Yau, K K W, K Wang and A H Lee 2003. Zero-inflated negative binomial mixed regression modeling of over-dispersed count data with extra zeros. Biometrical Journal, 45(4), 437-452. 
Copyright of Science \& Public Policy (SPP) is the property of Beech Tree Publishing and its content may not be copied or emailed to multiple sites or posted to a listserv without the copyright holder's express written permission. However, users may print, download, or email articles for individual use. 